Kansas State University Libraries

New Prairie Press

\title{
SHRINKAGE IN TERNARY MIXES OF CONTAINER MEDIA
}

Silvia Bures

Franklin A. Pokorny

Glenn O. Ware

Follow this and additional works at: https://newprairiepress.org/agstatconference

Part of the Agriculture Commons, and the Applied Statistics Commons

\section{(c) (1) $\Theta$}

This work is licensed under a Creative Commons Attribution-Noncommercial-No Derivative Works 4.0 License.

\section{Recommended Citation}

Bures, Silvia; Pokorny, Franklin A.; and Ware, Glenn O. (1991). "SHRINKAGE IN TERNARY MIXES OF CONTAINER MEDIA," Conference on Applied Statistics in Agriculture. https://doi.org/10.4148/

2475-7772.1416

This is brought to you for free and open access by the Conferences at New Prairie Press. It has been accepted for inclusion in Conference on Applied Statistics in Agriculture by an authorized administrator of New Prairie Press. For more information, please contact cads@k-state.edu. 


\title{
SHRINKAGE IN TERNARY MIXES OF CONTAINER MEDIA
}

\author{
Silvia Bures, Department of Horticulture \\ Franklin A. Pokorny, Department of Horticulture \\ Glenn O. Ware, Agricultural Experiment Stations \\ The University of Georgia
}

\begin{abstract}
Based on functional relationships established for binary mixes of container media, a mathematical model is proposed for ternary component mixtures. Shrinkage values are generated for three-component mixtures based on mathematical equations. Empirically observed shrinkage values for corresponding three-component mixtures are determined and used as the basis for assessing the reliability of the proposed mathematical model for characterizing shrinkage in mixtures of container media. Regression equations were developed and compared for both theoretical and empirical results.
\end{abstract}

Key Words: Three-component mixtures, response surfaces, linear programming

\section{INTRODUCTION}

Plant growth in containers differs significantly from that which takes place in natural soil, mainly due to the amount of medium available for the roots, and to the different soilwater relations that arise in container culture. It is consequently necessary in container culture to substitute what are known as artificial container media for natural soil. The significant growth that the plant container industry has experienced in the past 5-10 years has not only resulted in an increased demand for alternative materials but more emphasis is being placed on improved media formulation for optimum plant growth.

Many materials, either organic or inorganic, can be used in the formulation of container media (Raviv et al., 1986). Generally, none of these materials, by themselves, possess the necessary physical and/or chemical properties to support satisfactory plant growth. Thus, components are mixed in various proportions to achieve a medium environment which will support plant growth (Matkin et al., 1957). The determination of the various proportions for the components that provide required physical and/or chemical properties constitutes what is commonly referred to as a blending problem.

Blending problems can be defined as those where it is desired to achieve certain technical conditions in a product, which is obtained by mixing different ingredients in a certain way. The objective is to determine the nature and proportions of the components that satisfy a linear system of constraint equations on the product, subject to the minimization of cost or maximization of some benefit. One of the most widely used methodologies for the solution of a blending problem is linear programming (Chrétienne et al., 1980). Linear programming has been successfully utilized to solve blending problems in the manufacture of many products, including human food and beverages, animal feed products, pharmaceuticals, and chemicals. 
In determining the various proportions of container media components, not only are the materials different but each of the materials has a specific particle size distribution. When materials with different particle size distributions are mixed, finer particles fill the pores located between coarser particles, causing a general decrease in total volume. This phenomenon is known as shrinkage of the volume and is generally expressed in percent as one minus the ratio of the volume of the final mixture to the additive volume of the individual components multiplied by 100 . The application of linear programming for solution of a blending problem for container media requires knowledge of the final volume of the mixture. Thus, shrinkage and its effects on the system of equations is the main problem in applying this methodology. A preliminary study on the use of linear programming in soil mixture formulation was undertaken by Bures, et al. (1988).

Pokorny (1981) proposed the concept of computer selection of container media mixtures, as opposed to the traditional method which requires laboratory analysis and growth tests of multiple mixes prior to mix selection. Pokorny's (1981) concept is based on the development of estimating equations for bulk density (Pokorny et al., 1986), screen analysis (Gibson, 1984), water-release characteristics (Nash, 1989), hydrogen-ion activity (Nash and Pokorny, 1990a) and cation exchange capacity (Nash and Pokorny, 1990b) by which these properties may be estimated for any given volume mixture of individual components $(\mathrm{v} / \mathrm{v}$ ratios): An integral component of many of these estimating equations is a correction value for shrinkage. Final substrate volume and consequently physical and chemical properties are contingent upon how much shrinkage occurs when components of different particle sizes are mixed (Nash and Pokorny, 1990c).

Shrinkage curves for binary container mixtures have been developed (Nash and Pokorny, 1990c). Except for those blends where particle size distribution of components is similar (no apparent shrinkage), shrinkage follows a bilinear pattern, in the shape of an inverted $\mathrm{V}$, with maximum shrinkage at the $1: 1 \mathrm{v} / \mathrm{v}$ ratio and minimal (zero shrinkage) at the $1: 0$ and $0: 1 \mathrm{v} / \mathrm{v}$ ratios. An estimating equation for binary mixtures has been devised and tested (Bures and Pokorny, 1991) with the functional relationship being dependent only on the point where maximal reduction in bulk volume occurs. This opened the possibility of developing a model for 3-component (ternary) mixtures. The objective of this study was to develop a theoretical model for characterizing shrinkage in ternary mixtures of container media and test the validity and reliability of the proposed theoretical model.

\section{THEORETICAL VERSUS EXPERIMENTAL MODEL}

Linear equations accounting for shrinkage in ternary mixtures are based on the fact that if maximum shrinkage is obtained when $50 \%$ by volume of each of two components are blended, incorporation of an additional quantity of either component to the mixture will result in less shrinkage than the maximum. Furthermore, with a linear model and considering that the critical diameter ratio between particle sizes of the components is seldom obtained, this should also hold true when a third component is incorporated into the mixture. 
A theoretical model for estimating shrinkage for three components is proposed. Given three components (i), where $\mathrm{i}=1,2,3$ and the quantities $\left(\mathrm{x}_{\mathrm{i}}\right)$ denoting the volume proportion of each component such that $x_{i} \geq 0$ and $x_{1}+x_{2}+x_{3}=1.0$, then the amount of shrinkage for a mixture of three components is given by the following set of equations:

$$
\begin{aligned}
& \text { If } x_{1}>0.5, \quad S=2\left(x_{2} \operatorname{Smax}_{12}+x_{3} \operatorname{Smax}_{13}\right) \\
& \text { If } x_{2}>0.5, \quad S=2\left(x_{1} \operatorname{Smax}_{12}+x_{3} \operatorname{Smax}_{23}\right) \\
& \text { If } x_{3}>0.5, \quad S=2\left(x_{1} \operatorname{Smax}_{13}+x_{2} \operatorname{Smax}_{23}\right)
\end{aligned}
$$

If $x_{1}$ and $x_{2}$ and $x_{3} \leq 0.5$,

where

$$
\mathrm{S}=2 \sum_{i \neq j}^{3} \sum_{j}^{3} \mathrm{x}_{\mathrm{i}} \operatorname{Smax}_{\mathrm{ij}}-\left(\operatorname{Smax}_{12}+\operatorname{Smax}_{13}+\operatorname{Smax}_{23}\right)
$$

$\mathrm{S}=$ percent shrinkage of the ternary mixture and

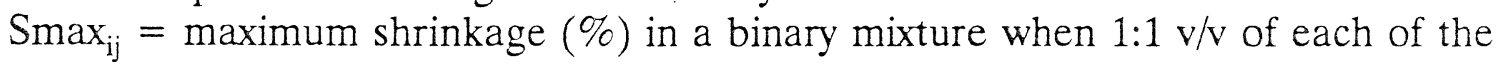
components $i$ and $j$ are blended $(i=1,2,3 ; j=1,2,3 ; i \neq j)$.

The requirement $x_{1}+x_{2}+x_{3}=1.0$ is a fundamental restriction for the simplest case of a mixture experiment (Cornell, 1990). This restriction appears to be a contradiction in this study, for when shrinkage is considered, the sum of the quantities of each of the components is not equal to 1.0. To circumvent this limitation in linear programming applications, shrinkage is considered to be a response value that is dependent upon component proportion.

A simplex coordinate system can be utilized for representing the values of the $x_{i}$ 's for three-component mixture experiments (Cornell et al., 1983). The coordinates can be plotted on triangular graph paper which has lines parallel to the three sides of an equilateral triangle (Figure 1). The vertices of the triangle represent individual components while the interior points of the triangle represent mixture blends in which all of the component proportions are nonzero, that is $x_{i}>0$ for $i=1,2$ and 3 . The centroid of the triangle corresponds to the mixture having equal proportions $(1 / 3,1 / 3,1 / 3)$ of each of the components.

Regression equations used to represent the functional relationship between the response measured and the ingredient proportions in mixture experiments differ from the ordinary regression problems (Cornell, 1990). Since the proportional components sum to 1 , the ordinary regression model for representing the functional relationship between shrinkage and the component proportions would be over parameterized. Thus, the following reparameterized quadratic and special cubic statistical models are used for representing this functional relationship:

Quadratic:

$$
E(Y)=B_{1} x_{1}+B_{2} x_{2}+B_{3} x_{3}+B_{12} x_{1} x_{2}+B_{13} x_{1} x_{3}+B_{23} x_{2} x_{3}
$$


Special cubic:

$$
E(Y)=B_{1} x_{1}+B_{2} x_{2}+B_{3} x_{3}+B_{12} x_{1} x_{2}+B_{13} x_{1} x_{3}+B_{23} x_{2} x_{3}+B_{123} x_{1} x_{2} x_{3}
$$

where

$E(Y)=$ expected value for shrinkage $(\%)$

$\mathrm{x}_{\mathrm{i}}=$ component proportions $\left(0 \leq \mathrm{x}_{\mathrm{i}} \leq 1\right)$

$B_{i}, B_{i j}$, and $B_{i j k}=$ regression coefficients to be estimated

The G3D procedure of SAS/GRAPH (SAS Institute Inc., 1987) was used for generating three-dimensional response surfaces for fitted equations. To plot three-dimensional surfaces, a linear transformation was performed on the simplex coordinate system $\left(\mathrm{x}_{1}, \mathrm{x}_{2}, \mathrm{x}_{3}\right)$ converting it into a two-dimensional Cartesian coordinate system $\left(\mathrm{V}_{1}, \mathrm{~V}_{2}\right)$ (Cornell et al., 1983).

Sand (particles 0.42 to $0.60 \mathrm{~mm}$ dia.), pine bark (particles 1.00 to $2.00 \mathrm{~mm} \mathrm{dia.)}$, and calcined clay (particles 2.38 to $4.75 \mathrm{~mm}$ dia.) were used to formulate test media for assessing the reliability of the proposed mathematical model. The experimental region corresponds to Figure 1 and represents all possible combinations of sand $\left(\mathrm{x}_{1}\right)$, pine bark $\left(\mathrm{x}_{2}\right)$, and calcined clay $\left(\mathrm{x}_{3}\right)$. The experimental design points consisted of a randomized complete block with 5 replicates for each of the 66 possible medium combinations where $x_{i}=0$ to 1.0 in increments of .1 for $\mathrm{i}=1,2$ and 3 .

Component bulk density was calculated using the procedure of Pokorny and Henny (1984). Mixtures were prepared by measuring the corresponding volume of each component so that the sum of the additive volumes was equal to 1.0. Shrinkage was determined using the methodology of Nash and Pokorny (1990c). Twenty replicates were used to characterize shrinkage (\%) at $1: 1 \mathrm{v} / \mathrm{v}$ for each of the three binary combinations (Table 1 ).

Table 1. Measured shrinkage (\%) of $1: 1 \mathrm{v} / \mathrm{v}$ binary container medium mixtures.

\begin{tabular}{llr}
$\begin{array}{l}\text { Binary Medium } \\
\text { Mixture }\end{array}$ & Notation & $\begin{array}{c}\text { Shrink } \\
(\%)\end{array}$ \\
\hline Sand - Pine Bark & $\operatorname{Smax}_{12}$ & 7.83 \\
Pine Bark - Calcined Clay & $\operatorname{Smax}_{23}$ & 3.00 \\
Sand - Calcined Clay & $\operatorname{Smax}_{13}$ & 10.61
\end{tabular}


Utilizing the shrinkage at the $1: 1 \mathrm{v} / \mathrm{v}$ for each pair of the three binary combinations, theoretical values were generated from equations 1-4 and are characterized in the experimental design space shown in Figure 2. Empirical results of the observed mean values for the randomized complete block design are characterized likewise in the experimental design space shown in Figure 3. Fifty-nine of the 66 experimental mean values were greater than their corresponding theoretical values. Under a null hypothesis of no difference between the experimental and theoretical values, a regression of the experimental values as a function of the theoretical values would require a zero intercept and unit slope. Estimates of the parameters from the regression analysis resulted in an intercept of 1.25 and slope of 1.17 with observed significance levels of $\mathrm{P}=.0001$ and $\mathrm{P}=.0001$, respectively. The significant intercept indicates a possible positive bias between the difference in experimental and theoretical values. However, the slope coefficient indicates that this bias may not be constant over all experimental combinations of components.

Table 2 shows the results of regression equations 5 and 6 applied to both theoretical and experimental values with both the quadratic and special cubic polynomial equations providing good fits. Although the special cubic equations only provide a slight improvement in the goodness of fit, the term $B_{123}$ of the special cubic polynomial is significant $(P<.05)$ for both models. Comparing the special cubic polynomials for the theoretical and experimental models reveals major differences in the estimates of the $B_{123}$ coefficients. This provides further evidence that the difference between the experimental and theoretical shrinkage values is not constant over all combinations of the three components. The response surfaces from the fitted equations for the special cubic polynomial are presented in Figure 4 which clearly shows the larger magnitude of the experimental shrinkage values.

Table 2. Regression equations for estimating shrinkage response for theoretical and experimental responses.

Model

Equation

$\mathrm{R}^{2 *}$

Quadratic

Experimental $\quad \mathrm{Y}=-1.59 \mathrm{x}_{1}-2.48 \mathrm{x}_{2}+2.01 \mathrm{x}_{3}+40.43 \mathrm{x}_{1} \mathrm{x}_{2}+46.18 \mathrm{x}_{1} \mathrm{x}_{3}+15.56 \mathrm{x}_{2} \mathrm{x}_{3}$

Theoretical $\quad Y=-0.75 x_{1}-0.75 x_{2}-0.75 x_{3}+27.39 x_{1} x_{2}+37.10 x_{1} x_{3}+10.49 x_{2} x_{3}$

Special Cubic

Experimental

$$
\begin{aligned}
Y= & -1.15 x_{1}-2.05 x_{2}+2.44 x_{3}+36.82 x_{1} x_{2}+42.57 x_{1} x_{3}+11.95 x_{2} x_{3} \\
& +31.57 x_{1} x_{2} x_{3} \\
Y= & -1.02 x_{1}-1.02 x_{2}-1.02 x_{3}+29.61 x_{1} x_{2}+39.32 x_{1} x_{3}+12.71 x_{2} x_{3} \\
& -19.44 x_{1} x_{2} x_{3}
\end{aligned}
$$

Theoretical

- $\mathrm{R}^{2}$ is defined as 1.0 minus the ratio of the residual sum of squares to the corrected total sum of squares. 


\section{CONCLUSION}

Equations for estimating shrinkage can be introduced into computer programs which allow for computer-design and selection of container media mixtures. These equations could either be based on a experimental regression model or derived from a theoretical model, assuming the adequacy of the theoretical model. At this point in time, we must question the complete adequacy of the theoretical approach in estimating shrinkage for container media mixtures. However, the results shown do not exclude its applicability from the practical point of view, giving an approximation to experimental shrinkage that is currently lacking and that could be considered and easily applied in computerized container media design.

Also, one should be cognizant that shrinkage values for the theoretical model are based solely on three laboratory measurements: the maximum shrinkage between the three binary combinations (sand - pine bark, sand - calcined clay, pine bark - calcined clay). These three determinations are easy and fast to obtain for any combinations of materials, saving a considerable amount of laboratory time when compared to the 66 determinations for the experimental model.

\section{LITERATURE CITED}

Bures, S., F. X. Martinez and M. Llorca. 1988. Preliminary study on the application of parametric linear programming in formulation of substrate mixes. Acta Hort. 221$141-152$.

Bures, S. and F. A. Pokorny. 1991. Equation for estimating shrinkage in binary mixtures of container media. HortScience. In Press.

Chrétienne, P., Y. Pesquex, and J. C. Grandjean. 1980. Algorithms et practique de programmation linéaire. Editions Technip. Paris, France.

Cornell, J. A. 1990. Experiments with Mixtures. 2nd ed. John Wiley \& Sons, Inc., New York.

Cornell, J. A., J. T. Shelton, R. Lynch, and G. F. Piepel. 1983. Plotting three-dimensional response surfaces for three-component mixtures or two-factor systems. Bul. 836. Univ. Fla., IFAS. Gainesville.

Gibson, P. G. 1984. "Prediction of selected physical properties of bark/sand container media from physical analyses of media components." MS Thesis, University of Georgia, Athens.

Matkin, O. A., Chandler, P. A., and K. F. Baker. 1957. Components and development of mixes. In: The U. C. System for producing healthy container-grown plants. K. F. Baker, ed. Univ. of Calif. Man. 23. 86-107. 
Nash, M. A. 1989. "Prediction of $\mathrm{H}$-ion activity, CEC, and water retention of potting media from laboratory analyses of individual components." PhD Dissertation, University of Georgia, Athens.

Nash, M. A. and F. A. Pokorny. 1990a. Prediction of H-ion activity of two-component potting media from analysis of components. Commun. in Soil Sci. Plant Anal. 21: 395-406.

Nash, M. A. and F. A. Pokorny. 1990b. Cation exchange capacity of two-component container media predicted from laboratory analysis of components. Commun. in Soil Sci. Plant Anal. 21: 705-715.

Nash, M. A. and F. A. Pokorny. 1990c. Shrinkage of selected two-component container media. Hortscience 25: 930-931.

Pokorny, F. A. 1981. Rx media - A concept for container plant production. ASAE paper No. 81-1089. St. Joseph, MI.

Pokorny, F. A. and B. K. Henny. 1984. Construction of a milled pine bark and sand potting medium from component particles. I. Bulk density: a tool for predicting component volumes. J. Amer. Soc. Hort. Sci. 109: 770-773.

Pokorny, F. A., P. G. Gibson, and M. G. Dunavent. 1986. Prediction of bulk density of pine bark and/or sand potting media from laboratory analyses of individual components. J. Amer. Soc. Hort. Sci. 111: 8-11.

Raviv, M. Y. Chen, and Y. Inbar. 1986. Peat and peat substitutes as growth media for container-grown plants. In: The role of organic matter in modem agriculture. Y. Chen and Y. Avnimelech, eds., 257-287. Martinus Nijhoff Publ. Dordrecht. The Netherlands.

SAS Institute Inc., 1987. SAS GRAPH Guide to Personal Computers, Version 6 Edition, Cary, N.C. 


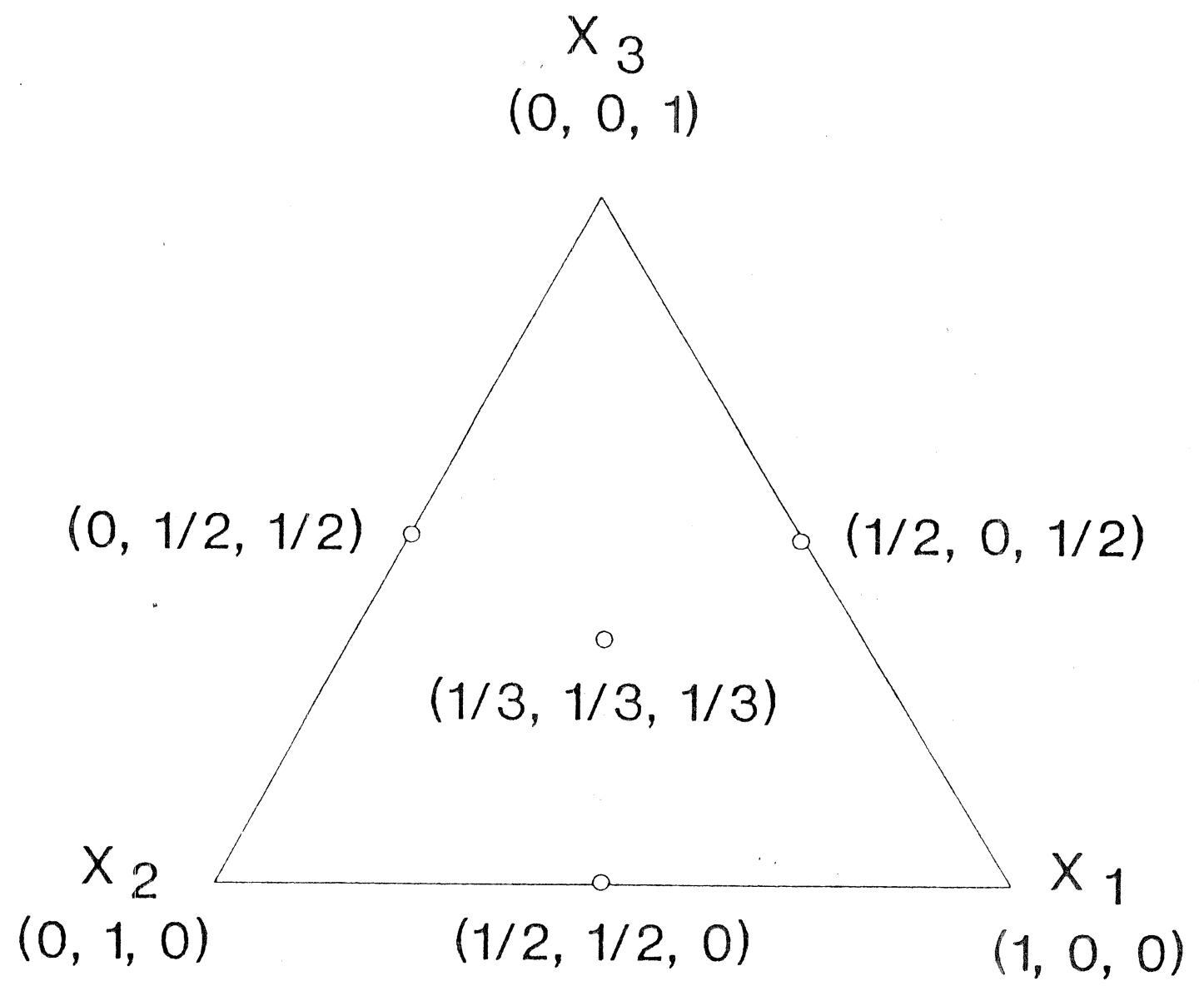

Figure 1. Experimental design space for three-component mixture. 


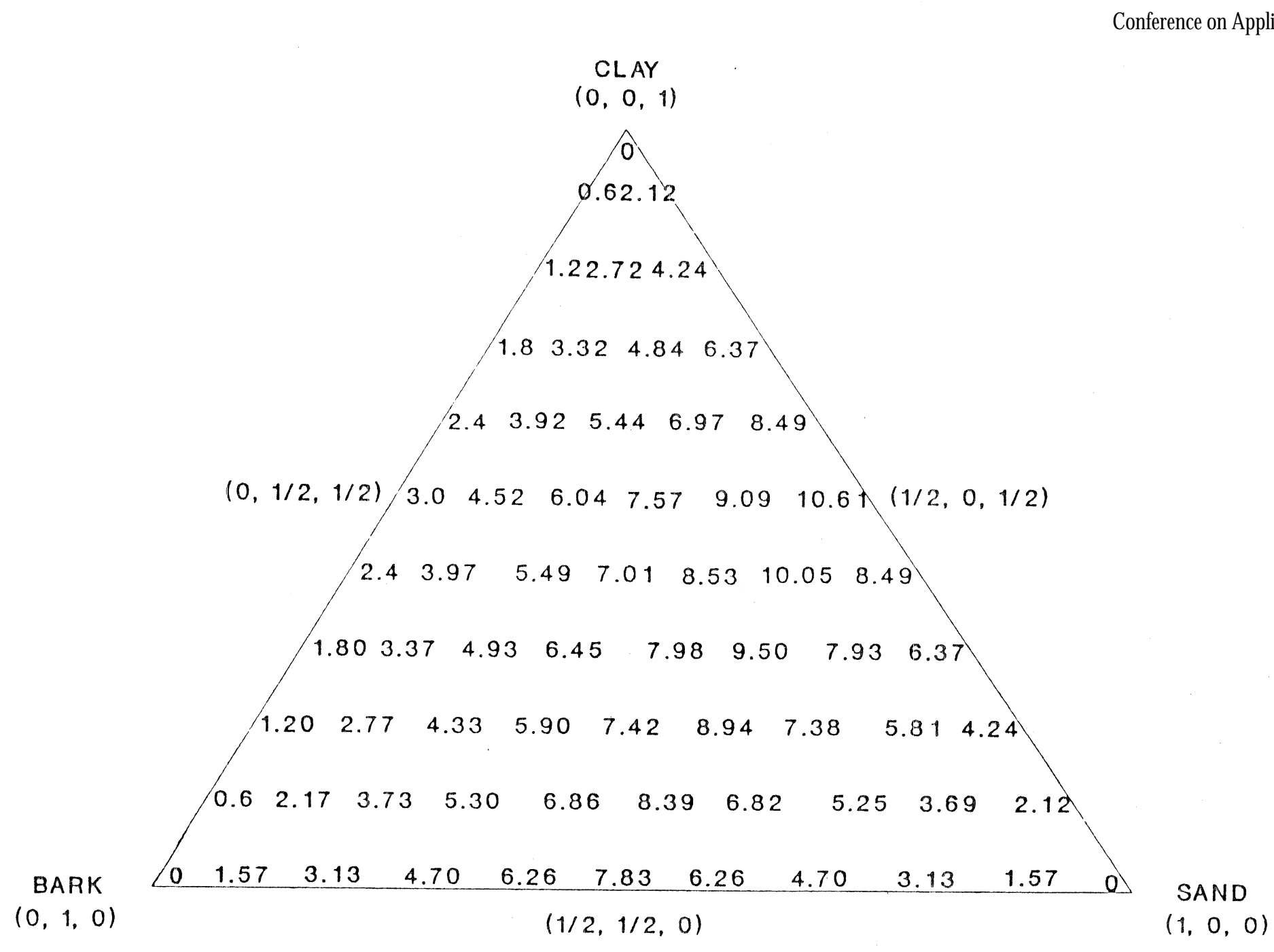

Figure 2. Theoretical shrinkage values for mixtures of bark, sand and calcined clay. 


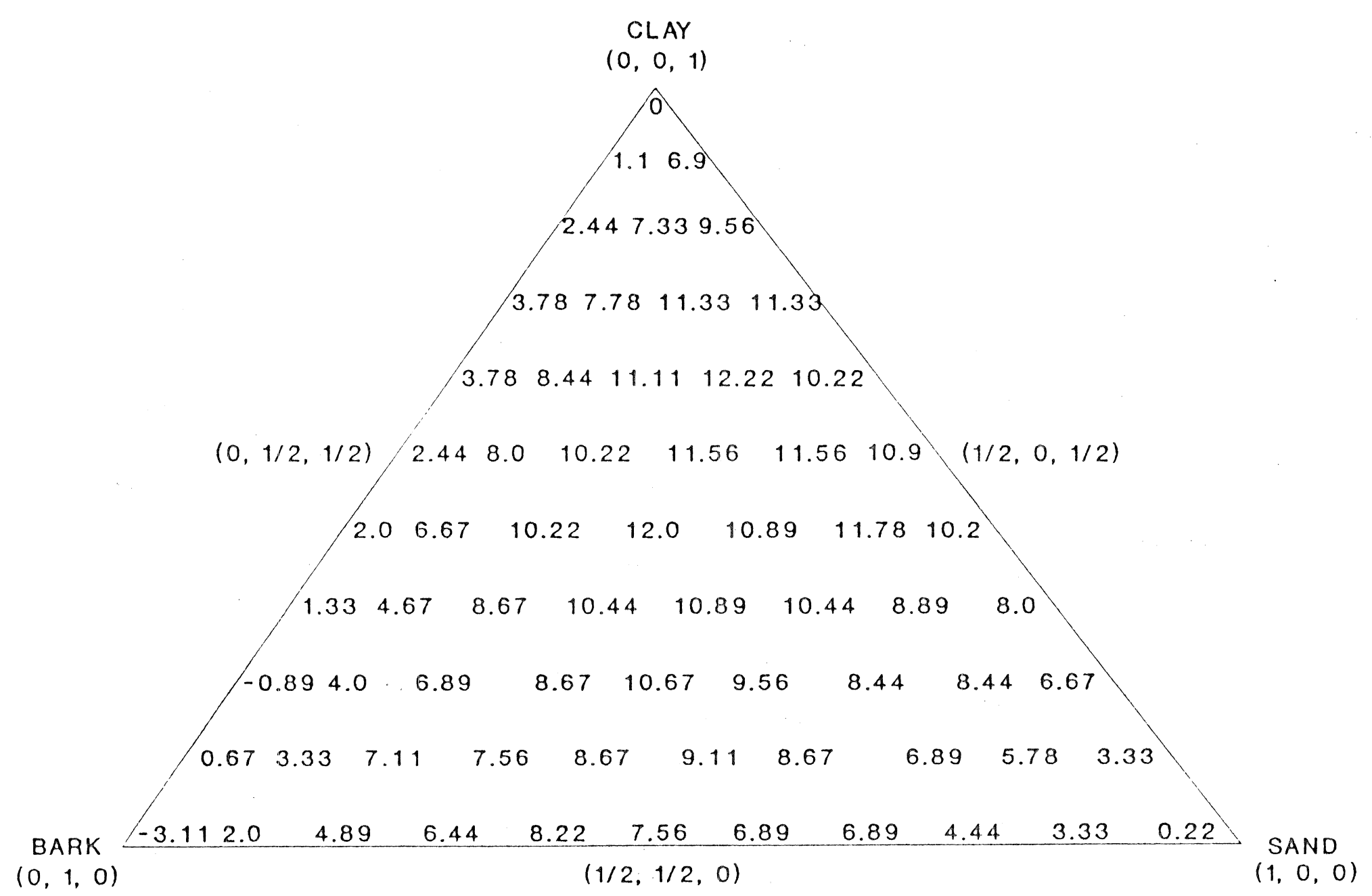

Figure 3. Experimental shrinkage values for mixtures of bark, sand and calcined clay. 

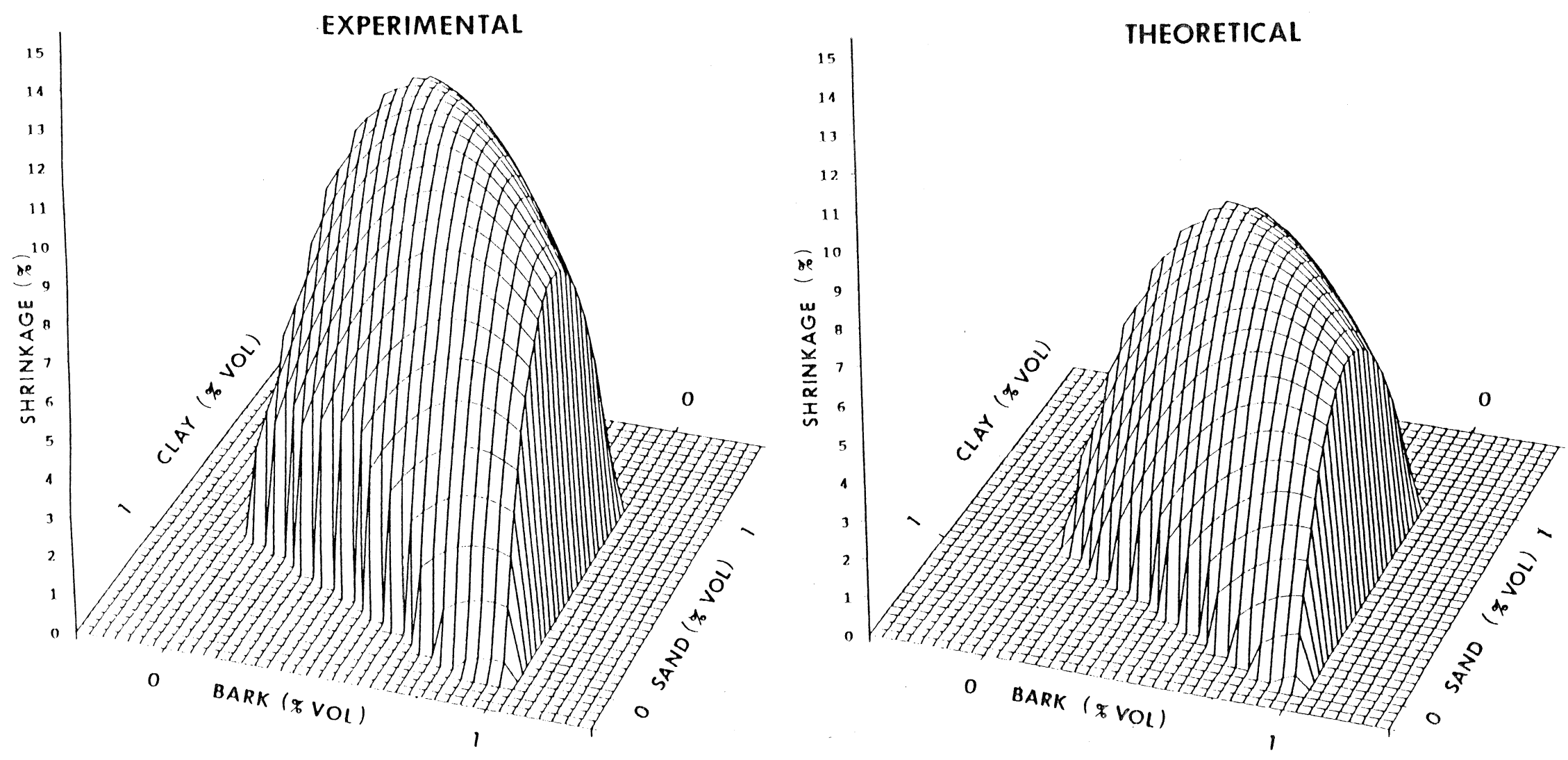

Figure 4. Comparison of regression response surfaces for experimental and theoretical shrinkage values. 